\title{
Towards a New Approach of Measure of Skills Applied to an Adaptive Assessments System Used in E-learning and E-recruitment
}

\author{
Ali Aajli \\ Laboratory of Computer Systems and Vision -LabSIV, \\ Faculty of science, Ibn Zohr University \\ Agadir, Morocco
}

\author{
Karim Afdel \\ Laboratory of Computer Systems and Vision LabSIV, \\ Faculty of science, Ibn Zohr University \\ Agadir, Morocco
}

\begin{abstract}
It is no coincidence, that the distance learning platforms are increasingly used in universities, colleges and companies offering effective and continuous training of their employees without constraint of time and space. The effectiveness of such a learning system depends mainly on the degree of information assimilated by the learner at the end of training. In this article, we focus on the conception and implementation of a system for measuring competence for the computer sciences. This system uses the model of the item response theory. The results provided by this system are presented to the student, as a dashboard. They will allow the teacher or tutor to have the necessary elements to monitor their learning by identifying the causes blocking and checking its achievements. This system can also help to improve the recruitment process of companies using it in a near-selection process of candidates for jobs.
\end{abstract}

Keywords-Assessment adaptive; E-Learning; skill level; item response theory; learner model; measuring skills; unit

\section{INTRODUCTION}

Evaluation refers to any systematic method based on quiz questions, tests, investigations and examinations to obtain information on the learner progress in a learning process [1]. It is important to clarify the context of evaluations in the learning process. The development and adoption of the latter directly affect the method of evaluation. The impact of choice of the evaluation type is very important and can have direct consequences on how to structure the course content and individual learning. In literature, there are several articles about this topic, but often there is a tendency to translate classical educational materials into distant learning without any transformation [2-5]. As a result, evaluation is not considered as an integral part of the learning activity and one of its important components, but it is often isolated from it.

The fact that the learner is found alone with his computer and not in a class, evaluation can transform his hesitant participation into an engagement with his course. it is going to inform him about his capacity of assimilation and to guide him through his training path. It is worth noting that the evaluation will lose its sense if it is not followed by fast, concise and focused feedback from the part of teacher or tutor. These feedbacks are good sources of motivation to accompany the learner. As for content, evaluation will help improve reviewing the ambiguous parts or improve assignments. Finally, evaluation can provide for tutor or teacher with the necessary information to supervise the student's learning process.

In this paper we describe our computer adaptive assessment that evaluates learners' knowledge in a particular technology field, and observe the evolution of the learner after a course of online distance learning (E-Learning). This system can also be used to improve the recruitment of candidates for employment.

In the following paragraph we will do an overview of the measuring skills approaches and discuss their limits in assessment systems in general and adaptive assessment systems in particular.

\section{SOME MEASURING SKILLS APPROACHES USED IN THE ASSESSMENT SYSTEMS}

There are two measuring skills approaches that are used in the assessments systems for E-Learning and recruitment process in companies; these approaches are those based on traditional assessments and those based on adaptive assessments.

\section{A. Approach based on traditional assessments}

This approach is one of most approaches used in ELearning assessments due to its easy implementation.

Traditional assessments such as formative and summative assessments that focus on the quantitative measurement of knowledge and skills of the assessee and allow appreciate the knowledge, skills and progress achieved. These assessments are mandatory examinations or not, providing a quantitative score indicating the degree of knowledge and skills of a candidate [6-9].

\section{B. Approche based on adaptive assessments}

There are many types of adaptive assessments used in ELearning, for example we cites the two-stage test and adaptive evaluation based on model of item response theory. 
- The two-stage tests administered initially a test director for all respondents to obtain a first level skill. Compared to the result obtained in the test director, a second test is selected and administered from several options to increase the accuracy of the results obtained in the first test [10-12].

- Adaptive assessments based entirely on model of item response theory (IRT), is based on the results of the IRT to calculate a priori estimator skill level which is generally based on the average population, then select an item based on the preliminary estimator skill level by maximizing the information using mathematical methods such as Bayesian maximization a posteriori (MAP) [13-16]

\section{Discussion}

The first approach has lot of limitations, because it concentrates more on the quantitative measurement of knowledge and skills. In fact it based on the hypothesis that all learners have the same level of ability in the field concerned and passed the same items, and therefore each learner required to respond to items that can be either too easy or too difficult for him, and this approach also maximizes the chance that the learner memorizes the items administered, then it can cause erroneous results.

The second approach is based entirely on model of item response theory (IRT) that gives good estimates of learners ability level, but since it is based on complex mathematical methods that require on the one hand the administration of a large number of items to achieve significant results that can cause a decentralization of learners, on the other hand require a complex implementation.

In this paper we present a new approach to measuring skills based on adaptive assessments using the model of item response theory (IRT), but without appeal to mathematical methods of IRT, these methods are replaced with others for remedied to the two limits listed below. To present this approach we begin by describing the learner model of our system, what is expressed in the following paragraph.

\section{LEARNER MODEL FOR ADAPTIVE ASSESSMENT SYSTEM}

The learner model is defined by two representations.

- A knowledge representation of the learner in the evaluated domain.

- A representation of the general information on the learner as the exercises he has done, how he has made (reasoning, solving process), the performance of these exercises, sections of the system selected, the time spent in each section [16-17].

Our adaptive assessment system models the knowledge representation of the learner using a hierarchy of concepts; each concept is associated with a part of the learner' knowledge in the evaluated domain.

The concepts are interconnected with two relationships fixed in advance by the tutor of domain:
- Relationship of pre-requisites that define the knowledge required to switch from one concept to another.

- Relationship of order that define the selected hierarchical order for all concepts of the domain.

For each concept we associate two variables:

- $\theta \mathrm{c}_{\mathrm{i}}$ : The learner ability level associated for the concept i.

- $\mathrm{F}_{\mathrm{i}}$ : Factor relevance of the concept, it is defined by the tutor of domain.

The figure below (Figure 1) illustrates the hierarchy of concepts of our adaptive assessment system.

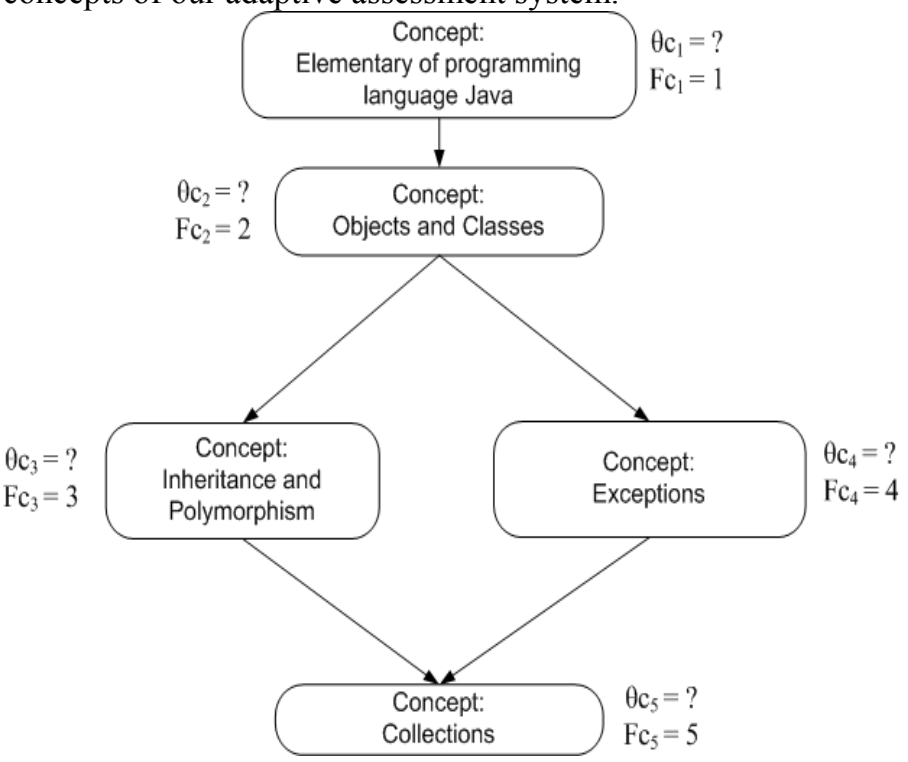

Figure 1. Hierarchy of concepts of adaptive assessment system

Each concept consists of several items that will be used in the adaptive assessment. The following paragraph present the Item Response Theory (IRT), that is used to characterize the system items.

\section{ITEM RESPONSE THEORY (IRT)}

The item response theory is a set of mathematical models for probabilistic representation of the characteristics of assessment items. These characteristics are used to determine the skill level of a respondent in a test [18].

There are different models in the item response theory, in our system we chose the one with two parameters noted 2 PL, which assigns for each item $u_{i}$ tow parameters $(b, c)$ with " $b$ " is the difficulty of the item and "c" is the pseudo-guessing of the item. The graphical representation of the probability of a correct response to the item $\mathrm{u}_{\mathrm{i}}(\mathrm{b}, \mathrm{c})$, depending on the ability level " $\theta$ ", takes the form shown in the figure below (Figure 2). 


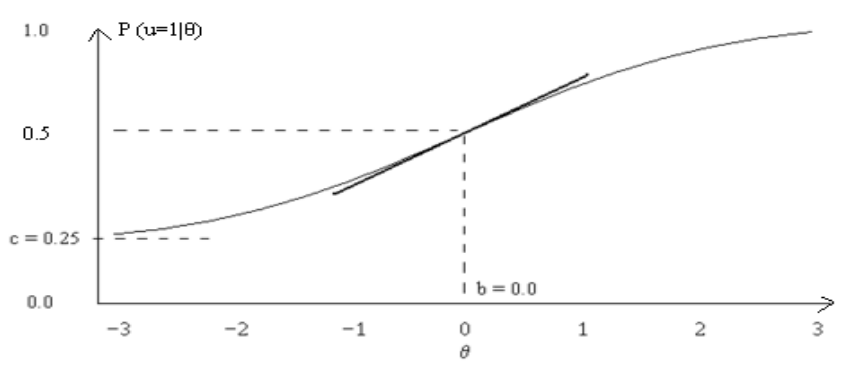

Figure 2. Characteristic curve of the item $\mathrm{u}_{\mathrm{i}}(\mathrm{b}, \mathrm{c})$

The general formula Characteristic Curve Item (CCI) is:

$$
P(u=1 \mid \theta, b, c)=c+\frac{1+c}{1+e^{-(\theta-b)}}
$$

In the curve, the parameter " $b$ " denotes the difficulty of the item, it is equal to the value of $\theta$ for which the probability of giving a correct answer is 0.5 it takes a value in the range $[-3,3]$. The parameter "c" refers to the probability for a respondent to obtain by chance the correct answer to the item; it is equal to the value of the lower asymptote of the item characteristic curve.

\section{CONSTRUCTION OF THE BANK OF ITEMS}

As indicated in the section "Learner model for adaptive assessment system" Each concept consists of a number of well-defined items, for the implementation of our adaptive assessment system, each concept contains 51 items as shown

\begin{tabular}{|c|c|c|c|}
\hline Concept 1 & Concept2 & \multirow{5}{*}{; } & Conceptj \\
\hline$\left.U_{1}\left(b_{1}, c\right)\right)_{c 1}$ & $U_{1}\left(b_{1}, c_{1}\right)_{2}$ & & $U_{1}\left(b_{1}, c\right)_{j j}$ \\
\hline$U_{2}\left(b_{2}, c_{2}\right)_{c 1}$ & $U_{2}\left(b_{2}, c_{2}\right) C_{2}$ & & $U_{2}\left(b_{2}, c_{2}\right)_{\mathrm{j}}$ \\
\hline$\cdots$ & ." & & $\ldots$ \\
\hline$U_{51}\left(b_{51}, C_{51}\right)_{c 1}$ & $U_{51}\left(b_{j 1}, C_{j i}\right)_{c_{2}}$ & & $U_{5}\left(b_{j 1}, C_{5 j}\right)_{c j}$ \\
\hline
\end{tabular}
in the figure below (Figure 3).

Figure 3. Example of the bank of items of the adaptive assessement system

For each item of the bank, the two parameters "b: difficulty of the item" and "c: pseudo-guessing" are precalculated based on the following rules:

- The parameter "b" takes a value in the range $[-3,3]$

- The parameter "c" of the easiest item is equal to 0.5

- The number of items in each concept is noted "M", for our system "M" is equal to 51 .
Under these rules the items will be indexed and listed in order

\begin{tabular}{|c|c|c|}
\hline Item Number & Difficulty & Guessing \\
\hline 1 & -3 & 0,5 \\
\hline 2 & $-2,88$ & 0,49 \\
\hline 3 & $-2,76$ & 0,48 \\
\hline 4 & $-2,64$ & 0,47 \\
\hline 5 & $-2,52$ & 0,46 \\
\hline 6 & $-2,4$ & 0,45 \\
\hline 7 & $-2,28$ & 0,44 \\
\hline 8 & $-2,16$ & 0,43 \\
\hline 9 & $-2,04$ & 0,42 \\
\hline 10 & $-1,92$ & 0,41 \\
\hline 11 & $-1,8$ & 0,4 \\
\hline 12 & $-1,68$ & 0,39 \\
\hline 13 & $-1,56$ & 0,38 \\
\hline 14 & $-1,44$ & 0,37 \\
\hline 15 & $-1,32$ & 0,36 \\
\hline 16 & $-1,2$ & 0,35 \\
\hline 17 & $-1,08$ & 0,34 \\
\hline 18 & $-0,96$ & 0,33 \\
\hline 19 & $-0,84$ & 0,32 \\
\hline 20 & $-0,72$ & 0,31 \\
\hline 21 & $-0,6$ & 0,3 \\
\hline 22 & $-0,48$ & 0,29 \\
\hline 23 & $-0,36$ & 0,28 \\
\hline 24 & $-0,24$ & 0,27 \\
\hline 25 & $-0,12$ & 0,26 \\
\hline 26 & 0 & 0,25 \\
\hline 27 & 0,12 & 0,24 \\
\hline 28 & 0,24 & 0,23 \\
\hline 29 & 0,36 & 0,22 \\
\hline 30 & 0,48 & 0,21 \\
\hline 31 & 0,6 & 0,2 \\
\hline 32 & 0,72 & 0,19 \\
\hline 33 & 0,84 & 0,18 \\
\hline 34 & 0,96 & 0,17 \\
\hline 35 & 1,08 & 0,16 \\
\hline 36 & 1,2 & 0,15 \\
\hline 37 & 1,32 & 0,14 \\
\hline 38 & 1,44 & 0,13 \\
\hline 39 & 1,56 & 0,12 \\
\hline 40 & 1,68 & 0,11 \\
\hline 41 & 1,8 & 0,1 \\
\hline 42 & 1,92 & 0,09 \\
\hline 43 & 2,04 & 0,08 \\
\hline 44 & 2,16 & 0,07 \\
\hline 45 & 2,28 & 0,06 \\
\hline 46 & 2,4 & 0,05 \\
\hline 47 & 2,52 & 0,04 \\
\hline 48 & 2,64 & 0,03 \\
\hline 49 & 2,76 & 0,02 \\
\hline 50 & 2,88 & 0,01 \\
\hline 51 & 3 & 0 \\
\hline
\end{tabular}
of increasing difficulty as shown in the figure below (Figure 4).

Figure 4. Indexing and classification of items in ascending order of difficulty

The following section describes the algorithm of the new measuring competence approach. 


\section{ALGORITHM OF THE NEW MEASURING COMPETENCE APPROACH}

\section{A. Algorithme}

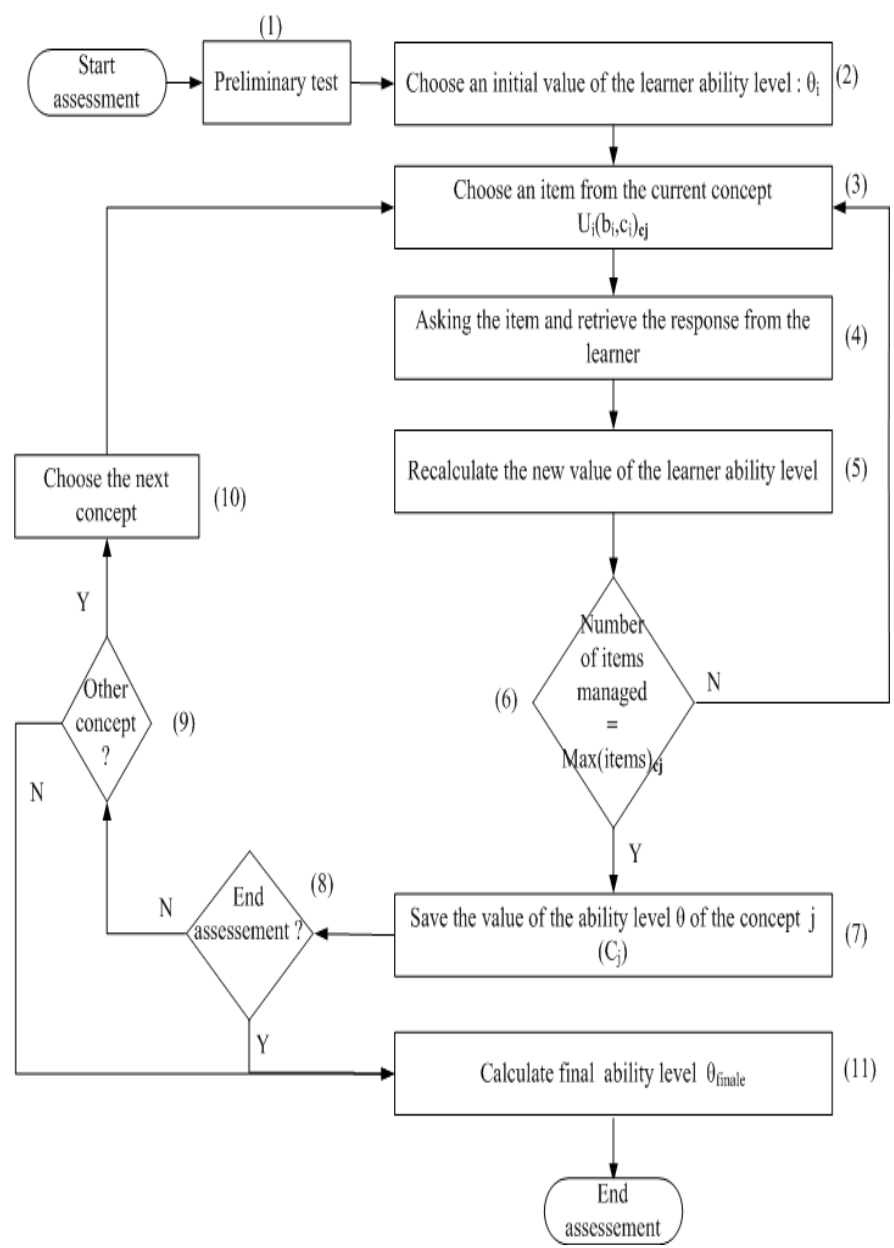

Figure 5. Algorithm of the new measuring skills approach

The following section gives details of each step of the algorithm of the new measuring skills approach.

\section{B. Details of the steps of the algorithm of the new measuring skills approach}

Step (1) is used to administer a preliminary test in the form of multiple choices for the learner; the sum of the correct answers is used to classify the learner into one of three levels: beginner, intermediate and expert.

Step (2) is used to choose the initial value of the learner' ability level, the table below explains the rule used for choosing the initial value.

\begin{tabular}{|l|l|}
\hline \multicolumn{1}{|c|}{ Learner level } & \multicolumn{1}{c|}{ Initial value of the learner ability } \\
\hline Beginner & A value in the range $\left[b_{10}, b_{20}\right]$ \\
\hline Intermediate & A value in the range $\left[b_{21}, b_{31}\right]$ \\
\hline Expert & A value in the range $\left[b_{32}, b_{42}\right]$ \\
\hline
\end{tabular}

For each learner level, the value of initial ability level is selected from 11 possible values.

Step (3) is used to choose an item from the current concept that will be administered to the learner. The choice of this item is based on the following criteria:

- The item should not be given previously in the assessment

- The system selects the item with the difficulty parameter is equal to the learner skill level

Steps (4) and (5) are used to retrieve the response of the learner to the selected item in the previous step, and depending on his response, the system re-estimate his skill level, based on the rules explained in the following figure.

\begin{tabular}{|c|c|c|}
\hline $\begin{array}{l}\text { Response of } \\
\text { the learner } \\
\text { to the item }\end{array}$ & \multicolumn{2}{|c|}{ Re-estimated the level of skill $\left(\theta_{(i+l)}\right)$} \\
\hline \multirow{2}{*}{ correct answer } & $\left(\right.$ i.e $b_{\mathrm{i}}<=b_{\text {Moy }}$ ) & $\theta_{(i+1)}=b_{(i+U I+1)}$ \\
\hline & Difficult item (i.e $\left.b_{i}>b_{\text {Moy }}\right)$ & $\theta_{(\mathrm{i}+1)}=\mathrm{b}_{(\mathrm{i}+\mathrm{UI})}$ \\
\hline wrong answer & \multicolumn{2}{|l|}{$\theta_{(\mathrm{i}+1)}=\mathrm{b}_{(\mathrm{i}-\mathrm{UD})}$} \\
\hline \multicolumn{3}{|c|}{$\begin{array}{l}\text { With: } \\
\text { - "i" is the index of the selected item in the previous step } \\
\text { - " } \theta_{(\mathrm{i}+1)} \text { " is the new value of the learner ability level } \\
\text { - " } \mathrm{b}_{\mathrm{Moy}} \text { " is the value of the average difficulty of all items, } \\
\text { for our system "b } \mathrm{b}_{\text {Moy }} \text { " is equal to } 0 \\
\text { - "UI" corresponds to the unit of incrementing } \\
\text { - "UD" corresponds to the unit of decrementing }\end{array}$} \\
\hline
\end{tabular}
The re-estimation formula for the skill level of the concept being explained by two possible cases:

- If the learner was correctly answered the item Ui(bi,ci)cj, then his skill level was underestimated then the system increase his level for the current concept.

- If the learner give à wrong answer to the item Ui(bi,ci)cj, then his skill level was over-estimated therefore the system decrease his level for the current concept.

To determine the two parameters "UI" and "UD" for our system, they must conform to the following three rules:

- At the end of the assessment, if all learners (beginner, intermediate or experts) respond correctly to all items, they must have the same equality of opportunities to achieve the maximum level of competence set by the $\operatorname{system}(\theta=3)$.

- At the end of the assessment, if all learners (beginner, intermediate or experts) respond incorrectly to all items, they must have the same equality of opportunities to achieve the minimum level of competence set by the system $(\theta=-3)$.

- For each concept, the adaptive assessment system sets a maximum number of items to be administered noted 
"N". For our system, "N" is equal to 10 items for each concept.

As taking account of these rules, the two parameters UI and UD are calculated as follows:

- $\mathrm{UI}=$ Round up $(\mathrm{M}-\mathrm{K}+1 / \mathrm{N})$

- $\mathrm{UD}=$ Round up $(\mathrm{K} / \mathrm{N})$

With $\mathrm{K}$ is the index of the first item of the current concept.

Step (6) is used to test the conditions necessary to switch to another concept:

- If the system has administered the maximum number of items specified in advance.

- If the time reserved to the assessment is completed

- If the system has administered the first or the last item of the concept.

If one of these conditions is not satisfied, the system re-starts from step 3 .

Step (7) is used to save the value of the skill level of current concept for future use.

Steps (8), (9) and (10) are used to test if the adaptive assessment is reached the end or the system must manage the items of next concept, based on the order defined in advance in the learner model.

Step (11) is used to calculate an estimate of the final skill level $\theta_{\text {final }}$; the system uses two parameters for each concept namely the level of competence " $\theta \mathrm{c}_{\mathrm{j}}$ " and factor of relevance " $F_{j}$ ". The figure below (Figure 5) illustrates the function of $\theta_{\text {final. }}$.

$$
\theta(\text { finale })=\frac{1}{\sum F_{j}} \sum_{j=1}^{N c} \theta c j * F j
$$

Figure 6. Rule calculates the $\theta_{\text {final }}$

$\mathrm{Nc}$ is the number of all concepts of domain.

At the end of the assessment, the system uses a matching based on the tutor experience feedback to link the value of skill level $\theta_{\text {final }}$ with the final estimated level of the learner.

\begin{tabular}{|c|c|}
\hline Final skill level $\theta_{\text {final }}$ & Learner level \\
\hline A value in the range $\left[b_{1}, b_{5}\right]$ & Elementary \\
\hline A value in the range $\left[b_{6}, b_{20}\right]$ & Beginner \\
\hline A value in the range $\left[b_{21}, b_{31}\right]$ & Intermediate \\
\hline A value in the range $\left[b_{32}, b_{46}\right]$ & Expert \\
\hline A value in the range $\left[\mathrm{b}_{47}, \mathrm{~b}_{51}\right]$ & Exceptional \\
\hline
\end{tabular}

The system provides a list of concepts mastered by the learner and those that it will provide more effort to raise its level. The following section describes the implementation of adaptive evaluation system using the new measuring skills approach described above.

\section{IMPLEMENTATION OF A COMPUTER ADAPTIVE ASSESSMENT SYSTEM FOR THE PROGRAMMING LANGUAGE JAVA}

In this section, we propose to present some of our functionalized system.

\section{A. Administering items to the learner}

This feature is available after authentication of the learner to assess, once the learner is authenticated via the login and password, an evaluation session is reserved for him and he can start the assessment of the Java programming language beginning, with the concept of "Elementary of Java" as shown in the figure below (Figure 7).

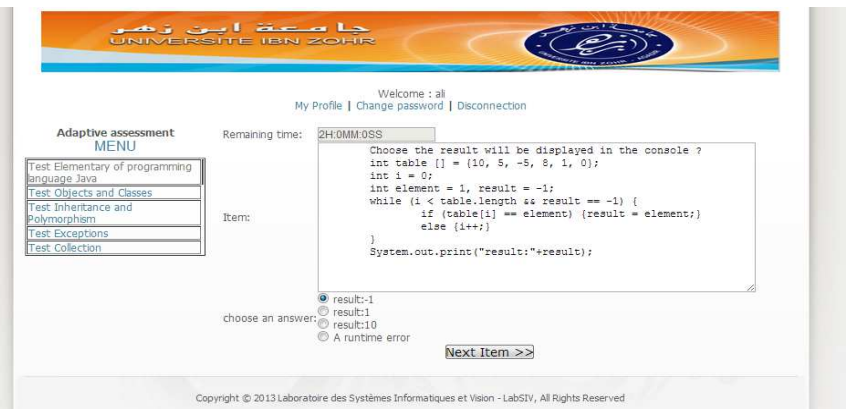

Figure 7. Administering items to the learner

\section{B. Get the results of the adaptive assessment of the Java programming language}

At the end of the assessment, the system provides the functionality to view the skill level of the learner, the administered items, the two units "UD" and "UI" and the number of items administered. The figure below (Figure 8) shows the result of the evaluation of the concept of "Elementary of Java".

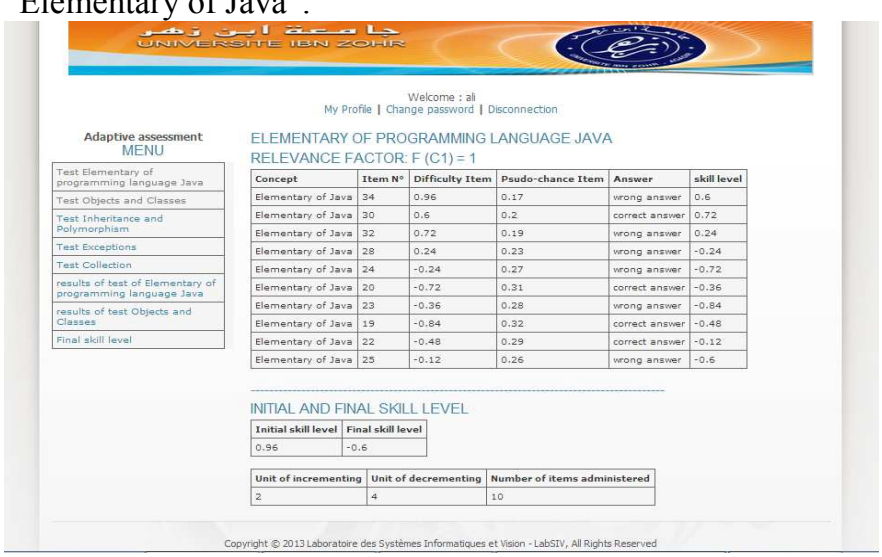

Figure 8. Results of the assessment concept « Elementary of Java » 


\section{The courses of some learners in the adaptive assessment system.}

For these learners, they have a different initial skill level. In the graphs $(9,10$ and 11$)$, the vertical axis corresponds to the indices of the items administered while the horizontal axis corresponds to the iterations of the assessments. The green and red symbols designate a correct or a wrong answer for administered items.

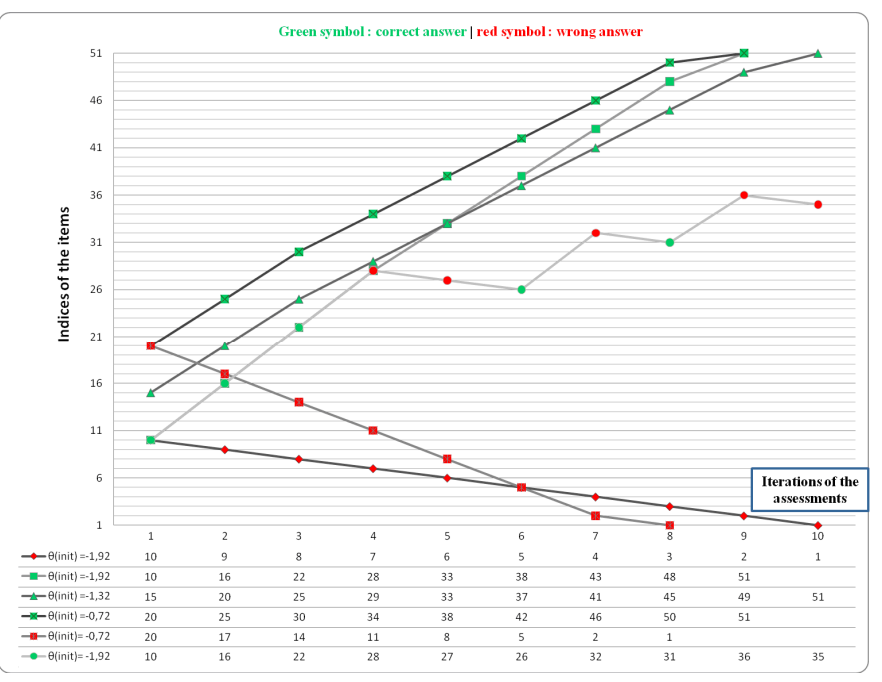

Figure 9. Course of six beginner learners

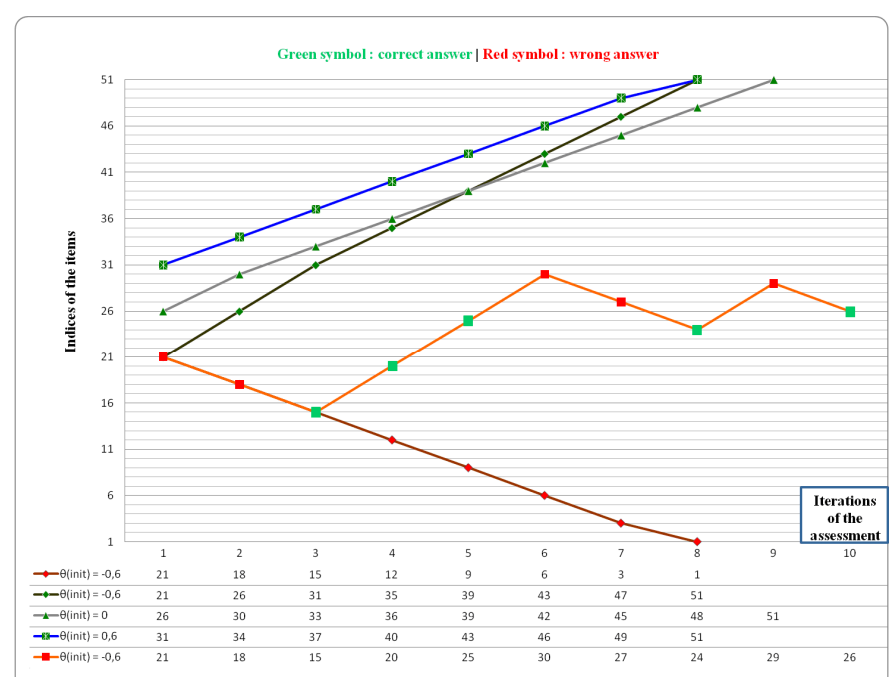

Figure 10. Course of five intermediate learners.

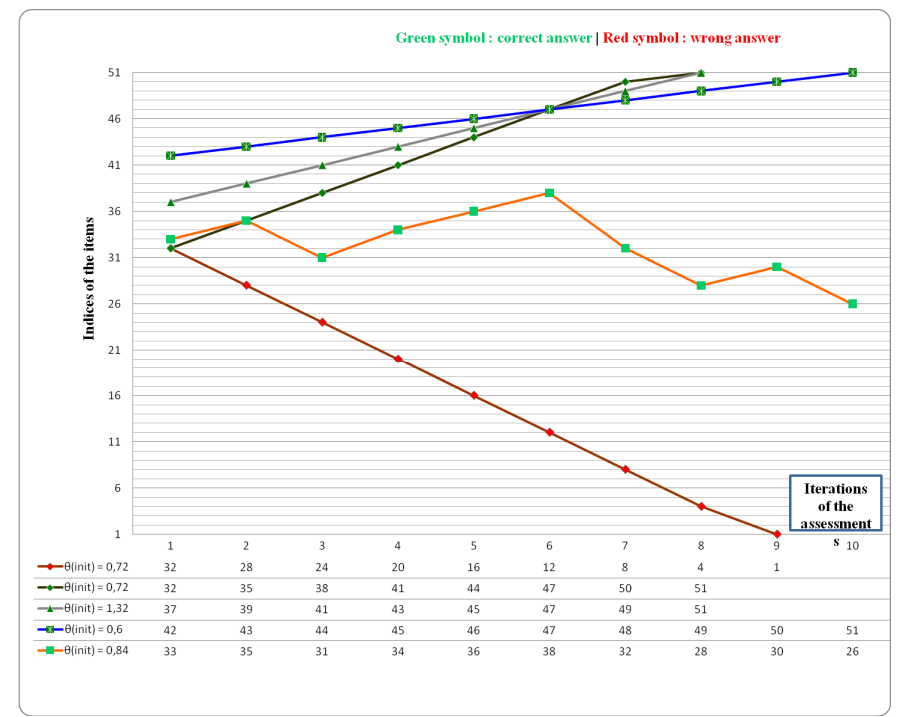

Figure 11. Course of five experienced learners.

The graphs above show that:

- The course of learners in the assessment depend firstly of their initial skill levels which vary between (-1.92) to $(+1.92)$, and secondly of the answers of the items administered.

- The initial skill level does not directly affect the final level of the learners, for example two learners (beginner and expert) having respectively the following skill levels $(-1.92)$ and $(+1.92)$ in start of evaluation, they can have at the end of the assessment the maximum skill level $(+3)$ if they answer correctly to all items.

- The system adapts to each level of learners who pass the assessment.

\section{CONCLUSION}

In this paper, we proposed a measuring skills approach and its implementation in an adaptive assessment system applied to the domain of Java programming language.

The first advantage of this approach is the integration of the notion of unit incrementing and decrementing of index of the items, which allows the evaluation system to adapt to the skill level of each learner, whether a beginner or an intermediate or an expert, while respecting their equality of opportunities to reach the maximum or minimum level skill sets by the system.

The second advantage of this approach is the choice of methods used to re-estimate the level of learners, these methods are not complex and the results obtained from using them generates a good adaptability of the system compared to the levels of learners, and a good estimate of their skills levels. 
The third advantage of this approach is the use of an average number of items per assessment, which facilitates the implementation of adaptive assessment system.

The system can be implemented in two different application domains

- In an assessment process after an online distance learning, to accompany the learner to customize their training path based on the results obtained.

- In the process of selection to improve the recruitment of candidates in the companies.

\section{REFERENCES}

[1] QUESTION MARK «Livre blanc - Les évaluations à travers le processus d'apprentissage»

http://www.questionmark.com/go/fra050704.htm

[2] CHENITI-BELCADHI, L.; HENZE, N.; BRAHAM, R. "Implementation of a Personalized Assessment Web Service" Advanced Learning Technologies, 2006. Sixth International Conference on Volume, Issue , 05-07 July 2006(pp586-590).

[3] KATHLEEN SCALISE \& BERNARD GIFFORD "Computer-Based Assessment n E-Learning: A Framework for Constructing "Intermediate Constraint " Questions and Tasks or echnology Platforms", The Journal of Technology, learning, and Assessment, Volume 4, Number $6 \cdot$ June 006.

[4] BARBOSA, H.; GARCIA, F. "Importance of online assessment in the elearning process" Information Technology Based Higher Education and Training, 2005. ITHET 2005. 6th International Conference on Volume, Issue, 7-9 July 2005 Page(s).

[5] SHEN R., TANG Y., ZHANG T., "The intelligent assessment system in web basesd distance learning education", Reno, NV 31 th ASEE/IEEE Frontiers in Education Conference October 10 - 13-2001

[6] Les évaluations à travers le processus d'apprentissage E.Shepherd, et J.Godwin .

[7] Sid Ahmed Benraouane, Guide pratique du e-learning - Conception, stratégie et pédagogie

[8] Howard W. (1990). Computerized Adaptive Testing: A primer. Educational Testing Service. Lawrence Erlbaum Associates, Inc. New Jersey 07642

[9] K.AFDEL, M. MACHKOUR, A. MOUDDEN, 2003, Collaborative Elearnning on ACOLAD, 4ème International Conference on Information Technology based Higher Education ITHET2003, 7-9 July 2003.

[10] Gruijter, Dato N. de ; Kamp, Leo J. Th. van der. ; Kamp, Leo J. T. van der "Statistical test theory for the behavioral sciences"

[11] R. Bertrand, Jean-Gay Balis, Gilles Raîche, Modèles de mesure : l'apport de la théorie des réponses aux items. Le testing adaptatif. $\mathrm{R}$. Bertrand et J.-G. Blais (Dirs) : Montréal : Presses de l'Université du Québec.

[12] R. Bertrand, Jean-Gay Balis, Gilles Raîche: Modèles de mesure: l'apport de la théorie des réponses aux items

[13] Le testing adaptatif. R. Bertrand et J.-G. Blais : Montréal : Presses de l'Université du Québec

[14] L.Laurencelle, S.Germain "Les estimateurs de capacité dans la théorie des réponses aux items et leur biais"

[15] Ronald K. Hambleton, Fundamentals of Item Response Theory

[16] Dirk Ifenthaler,Norbert M. Seel,Pablo Pirnay-Dummer,J. Michael Spector , Understanding Models for Learning and Instruction
[17] [REYE 04] Reye J. (2004) : " Student Modelling based on on belief networks, International Journal of Artificial Intelligence in Education, volume 14, pp 63-96.

[18] Christine DeMars, Item Response Theory

[19] Frank B. Baker (2011) The Basics Of Item Responsetheory, University of Wisconsin

\section{AUTHORS PROFILE}

\section{Dr. Karim AFDEL.}

Is Professor of higher education at the Faculty of Science of Agadir since a score of years. He currently directs several theses in varied disciplines of computer science, He is currently Director of the laboratory of Computer Systems and Vision (LabSIV).

\section{Ali AAJLI.}

Is Master's degree in systems and networks in 2008 in the university Ibn Zohr, Faculty of Science Agadir. Morocco. he prépart his Ph.D. in the laboratory of Computer Systems and Vision (LabSIV). Her doctorate study is interested by adaptability in assessement Learning

\section{Creative Commons Attribution License 4.0 (Attribution 4.0 International, CC BY 4.0)}

This article is published under the terms of the Creative Commons Attribution License 4.0 https://creativecommons.org/licenses/by/4.0/deed.en_US 